\title{
KAJIAN ETNOGRAFI KOMUNIKASI PADA GAYA BERKOMUNIKASI KOMUNITAS HANSAMO MODERN DANCE BOYS DI KOTA BANDUNG
}

\author{
Lucy Pujasari Supratman \& Adli Rafiqi \\ Program Studi Ilmu Komunikasi, Fakultas Komunikasi dan Bisnis, Telkom University*
}

\begin{abstract}
ABSTRAK
Salah satu komunitas yang cukup terkenal di kalangan anak muda pecinta grup musik boyband asal korea adalah komunitas Hansamo Modern Dance Boys di kota Bandung. Para anggota Hansamo Modern Dance Boys telah banyak menampilkan aksi panggung mereka di beberapa mall Bandung. Aksi panggung mereka terinspirasi oleh grup musik boyband korea Ze:A yang sangat diidolakan oleh seluruh anggota komunitas Hansamo Modern Dance Boys tersebut. Permasalahan yang diangkat dalam penelitian ini adalah mengenai bagaimana gaya berkomunikasi komunitas Hansamo Modern Dance Boys di kota Bandung dengan menggunakan pendekatan etnografi. Hasil penelitian menunjukkan bahwa terdapat gaya komunikasi verbal yang unik pada komunitas ini dimana mereka menggunakan bahasa pangggilan serta ungkapan bahasa korea dalam komunitas mereka saja. Selain itu, mereka menggunakan gaya komunikasi nonverbal yang berfungsi sebagai simbol kekompakan, pengikat mereka dengan komunitas, dan identitas pembeda mereka dengan komunitas pecinta musik korea lainnya.
\end{abstract}

Kata-kata kunci: Etnografi komunikasi, komunitas, gaya komunikasi, komunitas, K-Pop

\section{THE ETHNOGRAPHY COMMUNICATION OF HANSAMO MODERN DANCE BOYS COMMUNITY TO ITS COMMUNICATION STYLE IN BANDUNG CITY}

\section{ABSTRACT}

One of the famous communities among teenagers who love Korean boyband is Hansamo Modern Dance Boys in Bandung city. The members of Hansamo Modern Dance Boys have performed a lot of dance show in several Bandung malls. Their stage act is inspired by the music Korean boyband group Ze:A. Hansamo Modern Dance highly idolize the Ze:A where it is adopted in very performances. The research question is focused on how the communication style of Modern Dance Boys Hansamo community verbally and non verbally. The research used an ethnographic approach. The result of this research finds a unique style of verbal communication in the community in which they use the language nickname calling and the expressions of Korean language in their community. In addition, they use nonverbal communication style as a symbol of solidity, fastening the community, and distinctive identity with a other Korean boyband community.

Keywords: Communication ethnography, community, style of communication, community, K-Pop

\section{PENDAHULUAN}

Perkembangan Korean Pop (K-Pop) ke Indonesia dimulai dengan adanya boyband Super Junior asal Korea Selatan. Boyband Super Junior ini menyanyikan lagu berjudul 'sorry sorry' yang menjadikan Super Junior terkenal, termasuk di negara Indonesia. Gelombang Korea kemudian masuk ke industri di Indonesia dan segera memiliki banyak peminat pada jenis musik ini. Asih (2012: 1) menjelaskan gelombang Korea atau Hallyu merupakan istilah buatan yang bermakna pada peningkatan secara signifikan pengaruh budaya populer Korea di seluruh dunia. Gelombang Korea ini banyak digandrungi berbagai kalangan masyarakat Indonesia melalui makanan, minuman, pakaian, drama, hingga musik-musik korea. Musik Korea Selatan yang masuk ke Indonesia adalah musik dengan genre K-Pop yang terdiri dari

\footnotetext{
* Korespondensi: Dr. Lucy Pujasari Supratman, S.S., M.Si. Program Studi Ilmu Komunikasi, Fakultas Komunikasi dan Bisnis, Universitas Telkom. Email: doktorlucysupratman@gmail.com
} 
pop dance, elektro pop, hip hop, dan electronic music. Daya tarik musik K-Pop selain enak didengar juga memiliki para personil boyband dan girlband K-Pop dengan wajah oriental.

Ketenaran boyband dan girlband tentu tidakakan lepas tanpa dukungan penggemarnya di seluruh dunia. Sebutan komunitas pecinta boyband dan girlband Korea disebut dengan fandom. Fandom adalah sebutan umum untuk komunitas pecinta satu boyband atau girlband saja. Misalnya ELF (everlasting friend) adalah sebutan bagi fandom penggemar boyband asal Korea Super Junior saja. SONE adalah sebutan bagi fandom penggemar girlband asal Korea Girls Generation. HOTTEST adalah sebutan bagi fandom boyband asal korea 2PM, dan masih banyak lagi fandom-fandom lainnya di seluruh dunia.

Di kota Bandung sendiri banyak bermunculan fandom-fandom boyband atau girlband asal Korea. Fandom-fandom yang berada di kota Bandung sering mengadakan pertemuan dimana isi dari pertemuan tersebut diisi dengan acara lomba dan menonton video musik dari grup boyband atau girlband idola mereka. Sedangkan acara perlombaan divariasikan dengan lomba cover dance. Cover dance adalah tarian di mana fans yang tergabung dalam fandom menirukan gaya tampilan idola groupband idola mereka mulai dari lagu, gerakan tarian sampai kostum yang ditampilkan di atas panggung.

Motivasi mereka mengikuti perlombaan ini selain karena kecintaan pada idola mereka adalah piala serta uang yang cukup besar. Bahkan, mereka rela menyisihkan uang jajan dan menyewa studio tari agar bisa berlatih koreografi untuk mengikuti perlombaan cover dance. Tidak hanya itu, waktu belajar, bermain dan bekerja diatur dengan sangat baik agar dapat tetap kompak melakukan latihan-latihan persiapan perlombaan.

Salah satu grup cover dance yang dipilih dalam penelitian adalah Hansamo Modern Dance Boys (HMD Boys). Mereka adalah kumpulan remaja kota Bandung yang menggemari K-Pop dan memutuskan untuk membuat gup cover dance. HMD boys berdiri di bawah naungan menajemen Hansamo Family. Hansamo adalah singkatan dari bahasa korea "Hanguk eul Sarang Hanun Saram deurui moim" yang berarti 'Perkumpulan orang-orang yang menyukai Korea'. Hansamo didirikan pada tanggal 10 September 2006. Berdirinya komunitas HMD Boys diprakarsai oleh lima belas remaja Bandung yang sangat mengagumi budaya Korea. Kemudian proyek pembuatan komunitas ini berlanjut pada pembuatan komunitas identitas Bandung Hansamo.

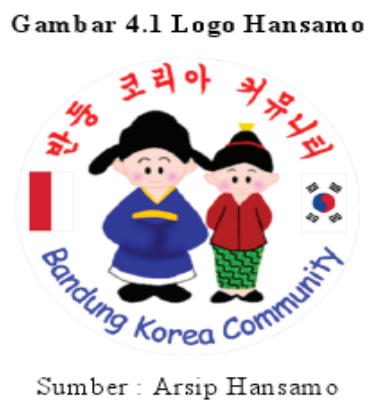

\section{Gambar 1. Logo Bandung Korea Community}

Setelah mendapatkan identitas yang dianggap dapat mewakili tujuan dari komunitas HMDBoys secarakeseluruhan, maka dimulailah kegiatan promosi untuk mendapatkan anggota. Kegiatan promosi ini melalui cara pemasangan poster dan pembagian flyer di tempat-tempat strategis seperti sekolah dan kampus. Selain kedua tempat tesebut, promosi juga dilakukan di mal-mal besar di kota Bandung. Setelah pembagian poster dan flyer, kegiatan promosi dilanjutkan dengan kerjasama dengan beberapa pihak, seperti Korean Association Bandung. Kegiatan Bandung Hansamo dinilai positif oleh Korean Association Badung dan memberi dukungan penuh pada setiap kegiatannya. Semenjak itu, Korean Association menjadi pembina dan pengawas semua kegiatan yang dilakukan oleh Bandung Hansamo.

Selain dari Korean Association, dukungan pada Bandung Hansamo datang dari Kedutaan Besar Korea untuk Indonesia. Pihak kedutaan besar Korea bersedia mendukung Bandung Hansamo secara penuh. Seiring berjalannya waktu, jumlah anggota Bandung Hansamo semakin bertambah. Bandung Hansamo pada awal pembentukannya ingin menjadikan sebagai wadah pertukaran budaya Korea dan Sunda, namun mereka terpaksa harus memilih salah satu budaya untuk menjadi fokus utama. Fokus tersebut adalah kebudayaan Korea. Hal ini disebabkan para anggota Bandung Hansamo lebih berminat untuk mempelajari kebudayaan Korea lebih dalam. Kemudian, diputuskanlah untuk fokus mengangkat kebudayaan Korea 
gratisan ajak kayak di be-mall atau balkot ha ha ha! Kalau misalkan gerakan kita udah kompak baru deh kita latihan di studio yang ada kacanya jadi kita bisa lihat kurangnya dimana" (Informan Aldi).

Sedangkan alasan mereka memilih berlatih tari di Jalan Durman karena lokasinya berada di tengah-tengah tempat tinggal anggota yang lain. Selain itu studio yang disewakan mampu menampung sembilan orang karena tempatnya cukup luas dibandingkan studio lain yang sempit dan tarifnya cukup mahal bila dibandingkan dengan di Jalan Durman.

Setelah latihan yang mereka lakukan sudah dirasa kompak dan lancar, mereka akan mengikuti perlombaan-perlombaan yang diadakan di Bandung atau di luar Bandung. Perlombaan cover dance sendiri biasa di adakan di mall-mall seperti di Festival City Link, Bandung Trade Mall, Metro Indah Mall, Lucky Square, dan beberapa tempat lainnya yang ada di kota Bandung. Event yang sering ada setiap bulan ini selalu diikuti oleh berbagai grup cover dance yang ada di Bandung maupun diluar Bandung. Peserta yang ikut berpartisipasi dalam acara-acara ini pun selalu bertambah. Komunitas HMD Boys tidak ingin ketinggalan momen perlombaan-perlombaan seperti ini. Menurut mereka, semakin sering mengikuti lomba maka semakin besar peluang kesempatan untuk eksis.

"Sejauh ini kita mengikuti lomba paling jauh di Grand Galaxy Bekasi. Gak menang sih tapi lumayan nambah pengalaman" (Wawancara Informan Dhanial)

Menang dan kalah memang menjadi sesuatu yang biasa dalam kompetisi. Mereka selalu menyikapinya dengan optimis dan bijak. Bila mereka tidak dapat memenangkan perlombaan, hal tersebut selalu mereka jadikan motivasi untuk terus memperbaiki kesalahan dan terus memberikan yang terbaik dengan cara berlatih dengan keras dan sungguh-sungguh.

"Alhamdulilah banget waktu di FCL kita dapet juara pertama dan grup kita langsung masuk kategori sunbae dari kategori hoobae" (Wawancara Informan Galih)

Dari kesalahan itulah akhirnya mereka dapat membuktikan bahwa mereka juga layak menjadi pemenang. Hal ini dibuktikan pada saat mereka mengikuti lomba di acara cover dance competition yang diadakan di Festival City Link, Bandung. Mereka meraih juara pertama dan langsung mengantarkan mereka menjadi kategori sunbae (senior).

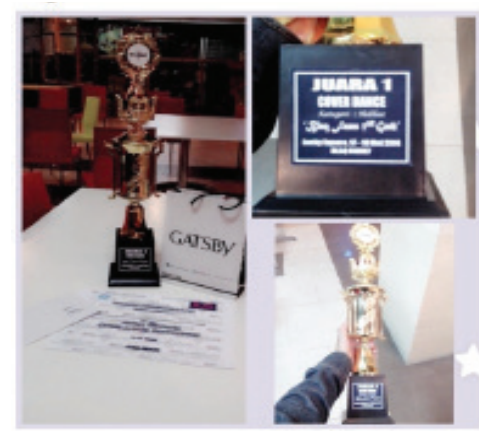

Gambar 3. Piala Juara 1 Komunitas HMD Boys di Festival City Link

Konsep lagu, gerakan dan kostum mereka sesuaikan dengan boyband idola mereka yaitu Ze:A. Kostum yang mereka pakai adalah kostum yang sengaja mereka buat menyerupai kostum yang pernah dipakai oleh boyband Ze:A sehingga mereka ingin tampil mirip dengan idolanya. Kostum tersebut bisa dikatakan merupakan bentuk komunikasi non verbal dari komunitas HMD Boys.

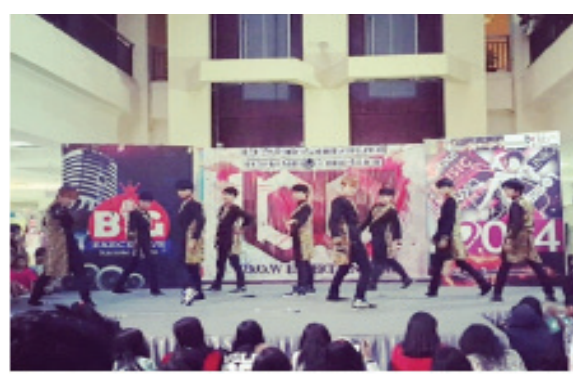

Sumber : Dokumentasi Peneliti

Gambar 4. Kostum Panggung Komunitas HMD Boys

Hasil penelitian yang kami lakukan mengenai bentuk-bentuk komunikasi verbal dan nonverbal pada komunitas HMD Boys cover dance dengan mengobservasi dan mewawancarai anggota komunitas Hansamo Modern Dance Boys. Adapun simbol-simbol verbal yang kami amati adalah berupa bahasa verbal yang biasa mereka gunakan ketika berkomunikasi dengan komunitasnya atau diluar komunitasnya, serta ungkapan dan simbol verbal dalam bahasa Korea yang mereka gunakan. Sedangkan simbol nonverbal meliputi (1) Pakaian, (2) gaya rambut, (3) gerakan, (4) kosmetik, (5) sentuhan, (6) proksemik,(7) paralinguistik. Bentuk 
sesuai dengan permintaan anggota. Berawal dari latar belakang itulah, penelitian ini mengangkat fokus pertanyaan penelitian, "Bagaimana kajian etnografi komunikasi pada komunitas Hansamo Modern Dance Boys di kota Bandung?

\section{METODE PENELITIAN}

Penelitian ini menggunakan pendekatan etnografi yang melihat interaksi antar individu dalam setting alamiahnya. Namun etnografi komunikasi yang kami lakukan berbeda dengan etnografi sosial. Kuswarno dalam bukunya etnografi komunikasi (2008: 35) menjelaskan bahwa pada etnografi komunikasi, yang menjadi fokus perhatian adalah perilaku komunikasi dengan tema kebudayaan tertentu, bukan keseluruhan perilaku seperti dalam etnografi. Adapun yang dimaksud dengan perilaku komunikasi menurut ilmu komunikasi adalah tindakan atau kegiatan seseorang, kelompok, atau khalayak ketika terlibat dalam proses komunikasi. Kelompok dalam hal ini adalah komunitas HMD Boys. Mereka merupakan sekelompok remaja yang sangat menggandrungi musik Korea dan melakukan proses komunikasi unik dalam kelompoknya dengan banyak mengitimasi cara berkomunikasi grup boyband Z:a.. Komunitas Hansamo ini selalu intens melakukan latihan menari di Jalan Wastukencana, Babakan Ciamis-Bandung, dan Studio Tari di Jalan Durman-Bandung.

Berikut adalah profil informan anggota komunitas HMD Boys:

Tabel 1. Nama Anggota Komunitas HMD Boys

\begin{tabular}{|c|l|c|}
\hline No & \multicolumn{1}{|c|}{ Nama } & Usia \\
\hline 1 & Galih Sapta Kusumah & 21 tahun \\
2 & $\begin{array}{l}\text { Ahyad Rosyada Jor- } \\
\text { diawan }\end{array}$ & 21 tahun \\
3 & Irwan Nurafandi Ahmad & 21 tahun \\
4 & Derby Erlangga & 20 tahun \\
5 & Ryan Febrian & 19 tahun \\
6 & Rizkyaldi Syahrir Mu- & 22 tahun \\
& harram & 25 tahun \\
7 & Dhanial Firdaus & 24 tahun \\
8 & Fachrul Rezka Fauzi & 19 tahun \\
9 & Muhammad Ramdani & \\
\hline
\end{tabular}

Daftar informan di atas dipilih karena termasuk ke dalam kriteria informan yang sesuai dengan penelitian ini. Penulis memiliki beberapa kriteria serta alasan pemilihan informan dalam penyusunan penelitian ini antara lain: (1) Informan merupakan anggota aktif komunitas HMD Boys yang masih sering tampil di lomba-lomba Cover dance Competition di Bandung, (2) Informan merupakan grup Cover dance yang sudah dikategorikan sebagai grup senior dan memiliki pengalaman banyak, (3) Informan merupakan grup yang berdiri dibawa manajemen Hansamo yang sudah terkenal karena sering mengadakan kegiatan K-Pop, dan (4) Informan merupakan grup Cover dance yang sering memenangkan juara di kompetisi K-Pop di Bandung maupun luar Bandung. Setelah data terkumpul dari para informan, kami kemudian menganalisis data tersebut dengan melakukan reduksi data, penyajian data dan penarikan kesimpulan.

\section{HASIL DAN PEMBAHASAN}

Boyband yang bernama Ze:A adalah boyband yang berasal dari Korea Selatan dibawah manajemen Star Empire. Boyband Ze:A memulai debut pertamanya pada tanggal 15 Januari 2010. Komunitas HMD Boys yang berasal dari kota Bandung adalah fandom dari boyband Ze:A. HMD Boys menuturkan pertama kali dipertemukan oleh manajemen Hansamo Bandung di bulan Maret 2012. Pada awalnya mereka belum terlalu akrab dan mengenal satu sama lain karena mereka berasal dari kampus, tempat bekerja dan tempat tinggal yang berbeda-beda. Alasan mereka bergabung dengan Hansamo Bandung karena mereka merasa nyaman dapat bergabung dengan komunitas yang memawadahi hobi dan kegemaran mereka terhadap budaya Korea. Mereka dapat menyalurkan hobi mereka di bidang menari cover dance. Selain itu, mereka juga mendapatkan banyak teman dan keluarga baru. Mereka merasa kegiatan yang mereka ikuti sangatlah positif karena waktu yang dihabiskan bersama-sama merupakan aktivitas bermanfaat. Para anggota komunitas HMD Boys mengisi waktu bersama dengan saling berbagi informasi, bertukar pikiran dan saling mengajarkan gerakan baru tarian Korean yang up to date. 
Para anggota komunitas HMD Boys sebetulnya memang tidak fasih berbahasa Korea. Namun, mereka senang menyelipkan ungkapan bahasa Korea tersebut pada saat berkomunikasi. Mereka sudah terbiasa berbicara menggunakan ungkapan dalam bahasa Korea karena terbawa suasana dan interaksi dengan orang-orang di sekitar komunitas pecinta music K-Pop.

Komunitas HMD Boys ingin selalu menampilkan yang terbaik pada saat mereka berada di atas panggung. Mereka sering melakukan latihan rutin untuk semakin meyempurnakan gerakan dan kekompakan mereka dalam menari. Mereka tidak ingin menampilkan gerakan yang asal-asalan. Penampilan mereka di atas panggung haruslah maksimal agar para penonton terhibur.

Fungsi kebersamaan dengan menggunakan simbol-simbol komunikasi seperti penggunaan kata serta ungkapan yang hanya dimengerti komunitas HMD Boys dapat merekatkan hubungan persadaraan mereka satu sama lain. Seperti yang dikatakan Supratman (2009: 57), "Dari ketertarikan minat yang sama tersebut, akhirnya pengungkapan diri lebih terbuka hingga terkuaklah penilaian konsep diri dari historis pengalaman empiris yang pernah mereka alami”. HMD Boys menambah keakraban dan rasa kekeluargaan diantara mereka dengan sering mengadakan perkumpulan bersama. Tempat yang mereka pilih untuk nongkrong tidak lepas dengan cafécafé yang berbau Korea, seperti Chingu Café yang terletak di Jalan Prof Eyckman. Disana juga tersedia makanan kesukaan mereka seperti Kimsci, Ramyeon, Bulgogi dan lainnya. Tidak jauh dari Chingu Café yang menjadi pilihan mereka, ada juga Mujigae café yang terletak di Cihampelas Walk. Mujigae merupakan Café alternatif lain yang mereka pilih untuk menghabiskan waktu bermain bersama karena tempatnya sama-sama bertema Korea.

Berikut diagram dari tujuan HMD Boys berkomunikasi dalam komunitas mereka:

Diagram 1. Tujuan Kohesivitas Dalam Komunitas HMD Boys

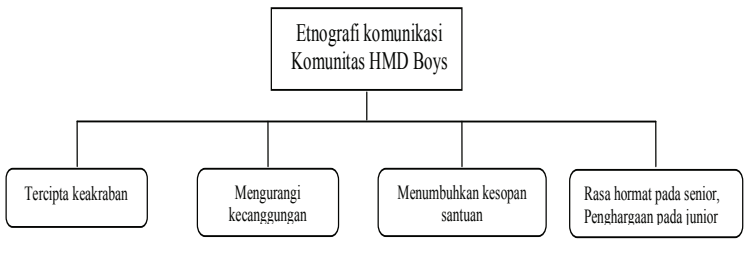

Para anggota HMD Boys berkomunikasi semakin efektif dalam komunitasnya. Para anggotajuga akan terlihatlebih akrab, mengurangi kecanggungan antar anggota komunitas serta menciptakan rasa kebersamaan dan persamaan visi misi. Selain itu, panggilan "Hyung" serta ungkapan bahasa Korea dapat menumbuhkan rasa saling menghargai dan kesopanan agar persaudaran dalam anggota komunitas dapat terus terjaga. Gaya komunikasi mereka yang efektif ini akhirnya membentuk kenyamanan masingmasing anggota komunitas. Hal ini terbukti dari bertahannya semua anggota HMD Boys yang sejak awal terbentuk, komunitas HMD Boys belum pernah mengalami konflik besar atau pergantian anggota.

Komunitas HMD Boys sering melakukan latihan rutin untuk semakin menyempurnakan gerakan dan kekompoakan mereka dalam menari. Mereka biasa berlatih sekali hingga tiga kali dalam seminggu. Mereka berlatih di Be-Mall, Jl. Naripan No. 89 Bandung, di studio dance di Jalan Durman atau di balai kota Bandung, Jl. Wastukencana No. 2 Bandung.

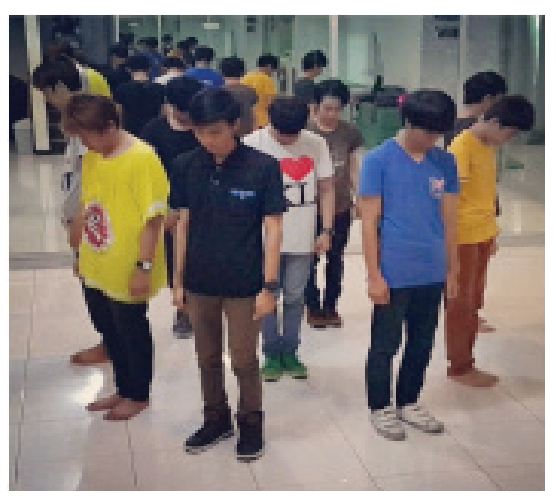

Gambar 2. Komunitas HMD Boys Sedang Melakukan Latihan Tari

Alasan mereka memilih berlatih di BeMall dan Balai Kota Bandung karena di tempat tersebut memang sering dipergunakan komunitas cover dance untuk berlatih. Selain gratis, mereka bisa leluasa berlatih dikarenakan lantai LG Be-Mall memang disediakan dari pihak mall untuk bebas dipakai masyarakat umum. Sedangkan di Balai Kota digunakan oleh komunitas cover dance pada siang hari untuk berlatih karena memiliki suasana nyaman dan banyak pepohonan rindang. Mereka juga bisa sekaligus berinteraksi dan bersosialisasi dengan komunitas lain yang sama-sama melakukan latihan rutin disana."Kalau kita lagi pada bokek, biasanya kita nyari tempat 
komunikasi nonverbal lain seperti 'bau-bauan' tidak kami temukan dilapangan, maka kami tidak mencantumkannya dalam penelitian. Hasil temuan yang terpilih, selanjutnya kami kategorisasikan sesuai kategori simbol verbal dan nonverbal yang telah kami rancang untuk kemudian dimaknai berdasarkan pengalaman yang dimiliki oleh seluruh anggota komunitas HMD Boys selaku pengguna komunikasi verbal dan nonverbal sebagai para informan dalam penelitian yang kami lakukan.

Simbol atau pesan verbal adalah semua jenis simbol yang menggunakan satu kata atau lebih. Hampir semua rangsangan wicara yang kita sadari termasuk ke dalam kategori pesan verbal disengaja, yaitu usahausaha yang dilakukan secara sadar untuk berhubungan dengan orang lain secara lisan. Bahasa dapat juga dianggap sebagai suatu sistem kode verbal (Mulyana dalam Heryadi \& Silvana, 2013).

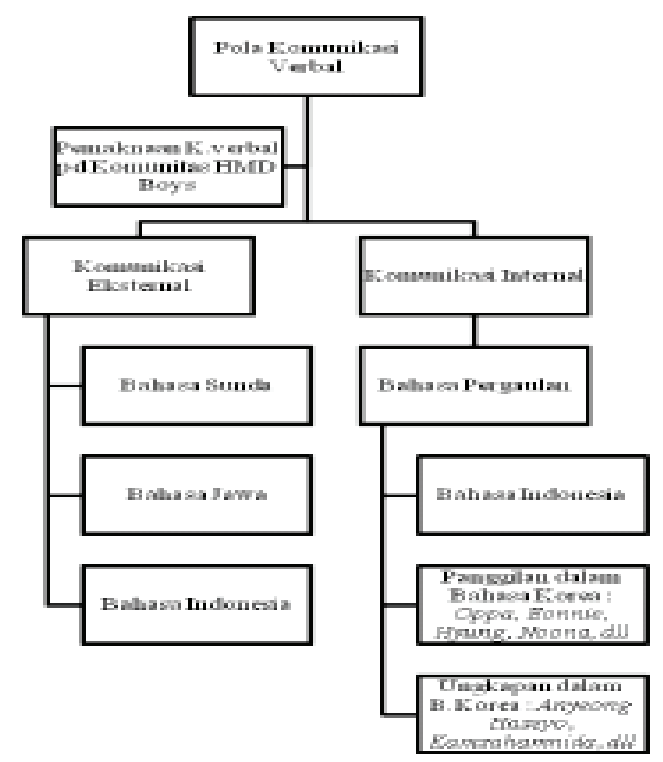

Diagram 2. Pola Komunikasi Verbal Komunitas HMD Boys

Book (1980) menyebutkan fungsi bahasa yaitu untuk berhubungan dengan orang lain dan untuk menciptakan koherensi dalam kehidupan kita. Dalam komunitas HMD Boys, bahasa Indonesia mereka gunakan untuk saling berhubungan dan mempersatukan fikiran mereka. Meskipun mereka berangkat dari latar belakang bahasa sehari-hari yang berbeda tetapi penggunaan bahasa Indonesia digunakan untuk menciptakan koherensi dalam komunitas mereka supaya apa yang mereka ucapkan dapat saling difahami satu sama lain.
Simbol verbal yang unik dari komunitas HMD Boys adalah adanya penggunaan katakata atau ungkapan dalam bahasa Korea yang mereka gunakan dalam komunitas HMD Boys ataupun dengan komunitas cover dance lainnya. Kata panggilan yang diberikan kepada Dhanial selaku anggota HMD Boys yang paling tua dipanngil "Hyung". "Hyung" adalah sebutan untuk laki-laki yang lebih tua dari laki-laki yang lebih muda. Meskipun sering dipanggil "Hyung" namun Dhanial mengaku tidak merasa risih dengan panggilan tersebut, karena menurutnya wajar saja melihat memang usia Dhanial paling tua di komunitas tersebut ditambah lagi komunitas mereka memang komunitas K-Pop dimana di Korea Selatan sendiri para anggota boyband dan girlband identik dengan panggilan hyung, oppa, noona, eonie. Berikut penulis uraikan kata panggilan dalam bahasa Korea yang sering diucapkan oleh komunitas cover dance HMD Boys di Bandung:

Tabel 2. Kata Panggilan Dalam Bahasa Korea

\begin{tabular}{|c|c|}
\hline & perempun \\
\hline Noona & Panggilun unthuk kaknk perewapum dnri adik laki-laki \\
\hline Oppa & Panggilan untuk kaknk laki-haki dnri adik perem punn \\
\hline Dongsaeng & Panggilnn untuk adik laki-lnki \\
\hline Agasshi & Punggilun untulk adik perewapum \\
\hline Chingu & Teman \\
\hline Nanuja Ching gN & Tewa m Laki-hki \\
\hline Yeoja Cimign & Teme an Perewapun \\
\hline Sunbabe & Senior \\
\hline Hoobae & Junior \\
\hline Rookie & Pendatang baru \\
\hline
\end{tabular}

Selain kata panggilan dalam bahasa Korea yang sering mereka gunakan ketika berinteraksi dengan komunitas K-Pop, bahasa atau ungkapan dalam bahasa Korea pun sering mereka gunakan. Meskipun mereka tidak fasih dan tidak lancar berbahasa Korea secara aktif namun kata-kata ungkapan dalam bahasa Korea sering mereka selipkan pada saat berbicara. Berikut penulis uraikan dalam bentuk tabel:

Tabel 3. Simbol Verbal Komunitas HMD Boys

\begin{tabular}{|c|c|}
\hline Bathasa Kerea & Arti \\
\hline Annyeong Faseyo & Salum \\
\hline Ganusahanuida & Terimea Kasih \\
\hline Gomawo & Terime Kasih (Infarmal) \\
\hline Mankate & Manf \\
\hline Yoboseyo & Hai \\
\hline Saranighaeyo & Aku cintn knmu \\
\hline Ommo! & Ya mpun! \\
\hline Hoaitiug! & Sem angat! \\
\hline Daebak & Keren \\
\hline Aegyo & Lucu \\
\hline Jryjya? & Serims? \\
\hline
\end{tabular}


Penggunaan ungkapan dalam bahasa Korea mereka gunakan pada saat berada di atas panggung. Seringnya pada saat perkenalan diatas panggung membuat mereka berbicara menirukan gaya bicara idola mereka "hana, dul, set! Anyeong haseyeo jigeumen HMD Boys imnida, kamsahamnida" (satu, dua, tiga! Salam perkenalkan kami dari HMD Boys, terima kasih). Mereka menggunakan ungkapan dan panggilan dalam bahasa Korea karena mereka ingin mengenal dunia di sekitar mereka dengan cara mempelajari apa saja yang menarik minat mereka. Minat mereka terhadap K-Pop menjadi alasan mereka menggunakan ungkapan dan panggilan dalam bahasa Korea.

Komunikasi non verbal adalah penting, sebab apa yang sering kita lakukan mempunyai makna jauh lebih penting daripada apa yang kita katakan. Menurut Budyatna dan Ganiem (2011: 110), komunikasi non verbal adalah setiap informasi atau emosi yang dikomunikasikan tanpamenggunakankata-kataataunonlinguistik. Kata-kata pada umumnya memicu salah satu sekumpulan alat indra seperti pendengaran. Sedangkan komunikasi non verbal dapat memicu sejumlah alat indra seperti penglihatan, penciuman, perasaan, hingga indra peraba. Dibawah ini kami akan menjelaskan mengenai pola komunikasi nonverbal pada komunitas HMD Boys yang meliputi (1) pakaian, (2) gaya rambut, (3) gerakan, (4) kosmetik,(5) sentuhan, (6) proksemik, (7) paralinguistik.

Penampilan pakaian dari komunitas HMD Boys tidak terlepas dari penampilan pakaian dari idolanya. Mereka mengaku lebih berkiblat ke cara berpakaian artisartis Korea dalam kesehariannya maupun diatas panggung. Seperti contoh kostum yang digunakan oleh HMD Boys pada saat mereka pentas, kostum yang mereka gunakan sengaja dibuat semirip mungkin dengan kostum dari boyband Ze:A.

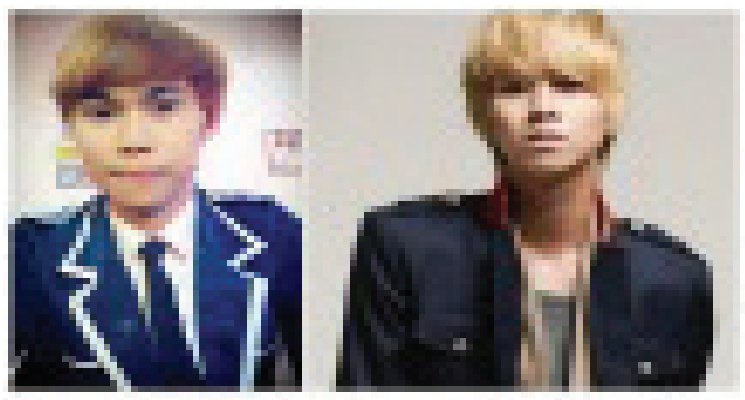

Gambar 6. Kesamaan warna rambut
Dari gambar diatas terlihat bahwa komunitas HMD Boys (Kiri) memang sengaja membuat kostum yang sama persis dengan idolanya yaitu Ze:A (kanan). Mereka ingin merepresentasikan dan menampilkan identitas mereka sebagai grup yang meng-cover boyband Ze:A. Sehingga pada saat orang lain terutama penggemar K-Pop melihat mereka, orang lain akan menilai mereka sebagai grup yang mengadopsi grup boyband Ze:A dengan menggunakan kostum yang sama persis.

Selain menyesuaikan dan meniru kostum dan pakaian idola mereka, gaya dan warna rambut mereka pun sengaja dibuat mirip dengan idolanya. Seperti yang dilakukan oleh Irwan dan Fauzi yang mencat rambutnya menjadi pirang agar terlihat mirip dan menjiwai perannya sebagai Minwoo Ze:A. Gaya rambut pirang dan sengaja dibuat gondrong menutupi jidat menurut Irwan agar dirinya lebih mendalami peran menjadi Minwoo dan sebagai bentuk fanatisme dari dirinya karena sangat mengidolakan sosok Minwoo Ze:A.

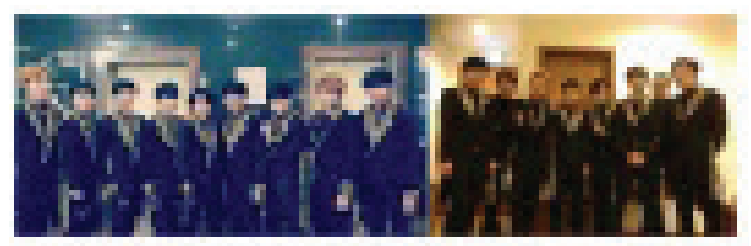

Gambar 5. Boyband Ze:A dari Korea (kanan), Komunitas HMD Boys (kiri)

Sementara anggota HMD Boys lain sengaja membiarkan gaya rambut mereka terlihat natural apa adanya. Meskipun begitu gaya rambut mereka memiliki kesamaan yaitu dibuat gondrong, lurus dan menutupi jidat dengan warna hitam alami. Member Ze:A pun rata-rata memiliki rambut gondrong dan lurus yang menutupi jidat mereka seperti poni.

Komunitas HMD Boys yang merupakan komunitas cover dance sering mempelajari gerakan-gerakan dari koreografi boyband idola mereka, Ze:A. Uniknya, gerakan dalam K-Pop bukan merupakan gerakan yang asal dibuat untuk melengkapi penampilan mereka, melainkan gerakan yang lebih kepada menegaskan isi lirik lagu yang mereka bawakan. Seperti contoh pada lagu Sorry Sorry, koreografi atau gerakannya dibuat seperti orang yang sedang meminta maaf. Begitu juga gerakan-gerakan yang 
dilakukan oleh komunitas HMD Boys yang mana gerakannya diadaptasi dari boyband idola mereka. Gerak tubuh merupakan simbol nonverbal menjadi suatu penegas dari pesan verbal yang disampaikan dalam lagu yang dibawakan.

Gambar berikut menunjukan koreografi dengan irik yang banyak berkata "tidak" ditegaskan dengan gerakan nonverbal mengangkat tangan terbuka ke depan seperti mengisyaratkan kata "tidak" atau "jangan".

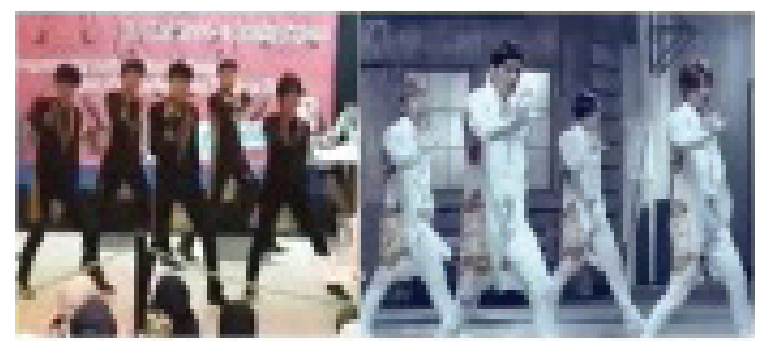

Gambar 7. Isyarat nonverbal dalam koreografi

Mengenai gaya berdandan, Komunitas HMD Boys menuturkan jika kosmetik yang mereka gunakan tidak begitu berlebihan, mereka hanya menggunakan beberapa kosmetik namun tetap dengan gaya yang natural. Kosmetik yang biasa mereka gunakan pada saat tampil diatas panggung adalah alas bedak, bedak, eyeliner dan hairspray.

Sentuhan dapat termasuk bersalaman, menggenggam tangan, berpelukan, dan sebagainya. Bentuk komunikasi sentuhan ini menyampaikan pesan untuk lebih menjalin hubungan emosional dengan komunikan.

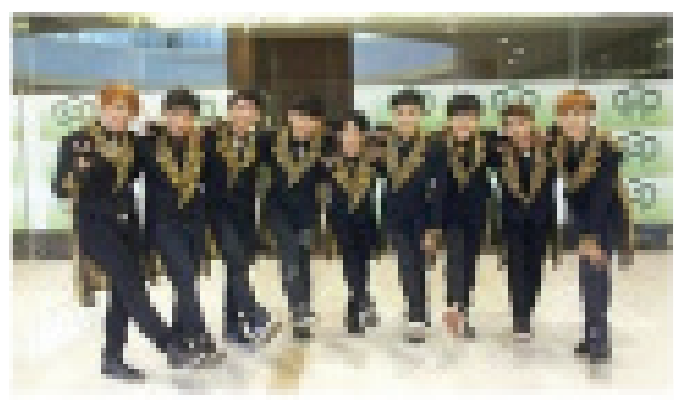

Gambar 8. Kekompakan komunitas HMD Boys

Gaya saling merangkul pundak yang dilakukan oleh komunitas HMD Boys ini mengisyaratkan kekompakan dan rasa kebersamaan mereka dalam membentuk sebuah komunitas. Sentuhan lain yang kami temukan di lapangan berupa berpegangan tangan pada saat doa bersama sebelum tampil diatas panggung dan melakukan high five pada saat setelah perform yang merupakan ekspresi suksesnya penampilan mereka.

Jarak keintiman komunitas HMD Boys termasuk kedalam jarak intim. Setelah melakukan latihan, mereka berkumpul terlebih dahulu dengan duduk secara melingkar dan merapat untuk membicarakan konsep dan perlombaan selanjutnya. Aldi yang merupakan ketua komunitas menjelaskan mengenai lagu dan lomba yang akan mereka ikuti. Para anggota lain mendengarkan Aldi secara fokus dan sesekali memberikan tanggapan serta komentar. Selain itu, kegiatan bermain atau nongkrong dan foto studio bersama membuat jarak kedekatan mereka semakin intim.

Paralinguistik dalam komunitas HMD Boys ketika mereka mengucapkan kata-kata atau ungkapan dalam bahasa Korea. Berikut tabelparalinguistik kata-kata dalam bahasa Korea yang sering diucapkan oleh komunitas HMD Boys:

Tabel 4. Paralinguitsik Komunitas HMD Boys

\begin{tabular}{|c|c|c|c|c|c|c|}
\hline No. & Bashasa Korea & Arti & Pinh & Vobume & Rufle & Rhyom \\
\hline 1 & $\begin{array}{c}\text { Aunyeong } \\
\text { Huseyo }\end{array}$ & Salnin & Tinggi & Kerns & Cepat & Teratur \\
\hline 2. & Gmusahanuvida & Terima Kasih & Tinggi & Karas & Ceppat & $\begin{array}{l}\text { Tirink } \\
\text { teratir }\end{array}$ \\
\hline 3. & Gomaniv & $\begin{array}{c}\text { Terillakasi } \\
\text { (Infannal) }\end{array}$ & Seding & Lembut & Lambet & Teratur \\
\hline 4 & Minuhae & Nonf & Rendhh & Lembut & Lambet & Teratur \\
\hline 5. & Yoboseyo & Hii & Tinggi & Karas & Cepat & $\begin{array}{l}\text { Tivink } \\
\text { Teratur }\end{array}$ \\
\hline 6. & Sarougineyo & $\begin{array}{l}\text { Alaucinth } \\
\text { kamu }\end{array}$ & Seding & Lembut & Lombet & Teratur \\
\hline 7. & Omemo! & Ya expen! & Tinggi & Karts & Lambet & Teratur \\
\hline 8. & Hivarimg! & Semingrant! & Tinggi & Karas & Ceput & Teratur \\
\hline 9. & Daebak & Karen & Tinggi & Karas & Ceput & Teratur \\
\hline
\end{tabular}

\section{SIMPULAN}

Berdasarkan hasil penelitian yang telah dilakukan, dapat diambil kesimpulan bahwa komunitas HMD Boys pada awalnya terbentuk karena adanya kesamaan minat dan hobi para anggotanya pada budaya Korea. Seluruh informan penelitian ini cenderung mengadaptasi penampilan dari boyband asal Korea Selatan Ze:A. Kesamaan minat para anggota komunitas pada grup boyband Korea Ze:A mendorong diri merka untuk berorientasi pada boyband tersebut. Para anggota HMD Boys sangat akrab mendiskusikan materi koreografi tarian cover dance, serta saling menciptakan rasa kebersamaan dan persamaan 
dalam komunitas karena mereka memiliki kesamaan makna.

Kebersamaan makna dalam benak masingmasing anggota komunitas merupakan wujud dari kekompakan mereka dalam komunitas. Gaya komunikasi verbal dan nonverbal yang mereka saling pahami bersama menjadi sesuatu yang mengikat kekompakan bagi setiap anggotanya. Penjiwaan yang mereka lakukan bukan hanya pada saat mereka diatas pentas saja, tetapi juga dalam kehidupan sehari-hari. Mereka sering menggunakan kaos fandom dalam beraktivitas di luar pentas seolah-olah anggota komunitas Hansamo Modern Dance ini ingin tetap terlihat seperti idola mereka dengan menggunakan kaos fandom berwarna hitam yang dipakai oleh boyband Ze:A.

Kehadiran komunitas ini sebenarnya telah memberikan warna pada beragamnya jenis perkembangan musik dunia, namun kearifan lokal pada kecintaan terhadap budaya setempat harus tetap dipertahankan. Komunitas dapat mengadaptasi koreografi idola mereka, grup boyband Ze:A dengan memadukan rasa kedaerahan. Semisal tetap menggunakan bahasa Indonesia dan bahasa Korea sekaligus saat menyapa para penonton. Mereka bisa juga meramu lagu korea dengan menerjemahkan lirik lagu bahasa Indonesia ke dalam lirik lagu berbahasa Indonesia saat tampil di panggung sebagai sebuah terobosan baru penampilan Hansamo Modern Dancer.

Penelitian tentang komunikasi dan interaksi mengenai lahirnya komunitas musik kota Bandung yang kian berkembang di bidang ilmu komunikasi masih terbatas. Oleh karena itu kami menyarankan untuk mengembangkan kembali penelitian yang lebih mendalam mengenai maraknya komunitas-komunitas musik yang bermunculan saat ini. Tidak hanya pada komunitas Hansamo Modern Dance saja, melainkan komunitas musik dengan genre beragam. Mengingat makin berkembangnya komunitas-komunitas musik tersebut yang sekarang banyak dibentuk dengan beragam motif tertentu. Sehingga penelitian-penelitian selanjutnya dapat memberikan kontribusi positif bagi kekayaan penelitian pada komunikasi verbal dan nonverbal, sebagai varian dari komunikasi antarpribadi.

\section{DAFTAR PUSTAKA}

Asih, A. (2012). Hallyu: fanatisme remaja pada budaya pop korea (studi tentang penggemar hallyu di kota yogyakarta. Yogyakarta: UNY.

Book, C.L, ed.(1980).Human communication: principles, contexts, and skills. New York: St. Martin's Press.

Budyatna, M. \& Ganiem. (2011). Teori komunikasi antar pribadi. Jakarta: Kencana.

Heryadi, H., \& Silvana, H. (2013). Komunikasi Antarbudaya Dalam Masyarakat Multikultur. Diakses dari http://journal.unpad. ac.id/jkk/article/view/6034/3145

Kuswarno, E. (2008). Etnografi komunikasi. Bandung: Widya Padjadjaran.

Rafiqi, A. 2014. Pola komunikasi verbal dan nonverbal pada komunitas HMD Boys. Bandung: Fakultas Komunikasi dan Bisnis, Telkom University.

Supratman, L. P. (2009). Tesis: Studi kasus pada pola komunikasi verbal dan nonverbal komunitas ebonics. Bandung: Program Pascasarjana Ilmu Komunikasi Universitas Padjadjaran. 